\title{
EXPERIMENTAL PERSPECTIVE OF ELECTROLYTIC MAGNETIC ABRASIVE MACHINING: A REVIEW
}

\begin{tabular}{|c|c|c|}
\hline Amit Singh & Vinod Yadava & Venkesteswara Rao Komma \\
Mechanical Engineering Department & Mechanical Engineering Department & Mechanical Engineering Department \\
Motilal Nehru National Institute of & Motilal Nehru National Institute of & Motilal Nehru National Institute of \\
Technology Allahabad & Technology Allahabad & Technology Allahabad \\
Allahabad, India, 211004 & Allahabad, India, 211004 & Allahabad, India, 211004 \\
amit080888@gmail.com & vinody@ mnnit.ac.in & kvrao@mnnit.ac.in \\
\hline
\end{tabular}

\begin{abstract}
The machinist curiosity of exploring better machining and finishing processes beyond conventional machining processes for difficult to machine material has lead the genesis of hybrid processes. Electrolytic Magnetic Abrasive Machining (EMAM) process is one of the hybrid processes evolved from two constituent processes, namely Magnetic Abrasive Machining (MAM) and Electrochemical Machining (ECM). EMAM process takes advantage of both the processes for better machining performance and restricts to electrically conductive materials. The workpiece may be flat or cylindrical either on internal or external surface. Although few experimental setups have come up but scope for developing better indigenous setup still remains open. Herein the effect of process parameters and performance parameters has been highlighted. The untapped experimental potential of EMAM process at industrial implementation level is in open domain of research in hybrid machining. Experimental findings have been summarized for superior performance parameter and better setup.

Keywords- Magnetic Abrasive Machining; Electrochemical machining, Hybrid process, Experimental process, Electrolytic Magnetic Abrasive Machining
\end{abstract}

\section{INTRODUCTION}

The requirement of superior materials or products to perform well at elevated temperatures and remain corrosion resistant, fatigue resistant has compelled researchers to develop better viable machining process for their development. One of such machining requirement is studied for electrically conductive hard materials. Magnetic Abrasive Finishing process is used from past decade for finishing hard materials but its viability is restricted to a critical value. Similarly, Electrochemical Machining process too becomes non- reactive after some time. Hence, hybrid process becomes significant for better machining and finishing. The Electrolytic Magnetic Abrasive Machining is hybrid machining process evolved with the synergetic effect of Magnetic Abrasive Machining and Electrochemical Machining.

Bayoumi et al. (1995) experimentally observed that at higher surface roughness the crack initiation becomes quick and subsequently fatigue life decreases [1]. So, fatigue resistant property can be supported by improving surface finish. Shinmura et al. (1990) performed MAF experimentation on SS441 steel to improve surface finish [2]. Chang et al. (2001) performed experiment on cylindrical workpiece for better surface finish and material removal [3]. Some researchers experimentally observed the effect of vibration assistance in MAF[9, 10]. However, MAF process becomes ineffective after certain time and it needs to overcome. ECM is process of machining at small thickness and later becomes inert to electrolyte reaction by forming a passive layer. Therefore, the hybrid process combining both as constituent processes evolved. Yan et al. (2003) reported working efficiency of EMAF much higher than MAF matches low electrolytic current density closely to avoid electrolysis and provide permissible condition for accelerating the removal of material and simultaneously obtain superior finished surface [26]. Fang et al. (2002) reported magnetic field electrochemistry on removal rate, finishing efficiency for electrochemical machining [25]. Du et al. reported research on plane surface EMAF of nickel based superalloy GH4169 and showed that the process efficiency improved by $50 \%$. They analyzed surface energy spectrum, ultra depth 3D- Electron Microscopy for 20 min [32]. Kim et al. reported on Magnetic Electrolytic Abrasive Polishing (MEAP) process, theoretical and experimental explanation on stock removal was confirmed $[33,34]$. The hard materials are difficult to machining and finishing. The cutting tool materials are also not easily reproducible due to high hardness. The hardened steels, superalloy and composites are also in the category of difficult to machine materials. The superalloys are either iron-based alloys, nickel-based alloys or cobalt based alloys such as GH4169, Inconel 823 and $6061 \mathrm{Al} / \mathrm{Al}_{2} \mathrm{O}_{3}$ composite etc.

This review emphasizes experimental setup development aspect of EMAM process. The performance parameters improve within same duration on different configuration based on process parameters.

\section{EXPERIMENTAL SETUP PERSPECTIVE}

The development of experimental setup is an exhaustive setup towards exploring manufacturing facts with different configurations of advanced machining and finishing processes. The development of experimental setup of Electrolytic Magnetic Abrasive Machining process is highlighted. The three different configurations of EMAM process evolved after applying ECM on MAF process. Researchers have reported setup of different configurations separately, namely Cylindrical-EMAM (C-EMAM) for external surface, Cylindrical-EMAM for internal surface and Plane-EMAM depending on workpiece machining surface interaction. Chang et al. (2002) reported experimentation on SKD11 (HRC55) cylindrical workpiece with SiC abrasive slurry distilled water [3]. Yan et al. (2003) reported experimentation 
Asia Pacific Journals

on SKD11 (HRC61) cylindrical bar using C-EMAM. They used $\mathrm{NaNO}_{3}$ passive electrolyte during experimentation [26]. Judal et al. (2014) reported C-EMAM experiment on AISI304 cylindrical workpiece with $\mathrm{SiC}$ abrasive, $\mathrm{NaNO}_{3}$ passive electrolyte. [28].

\section{A. Mechanism of the Magnetic Abrasive Machining}

In MAF process, the workpiece is kept between the North Pole and South Poles of a magnet or electromagnet. The working gap between the workpiece and the magnet is filled with MAPs. The MAPs join each other along the lines of magnetic force and form a flexible magnetic abrasive brush between the workpiece and each magnetic pole. Due to rotation of workpiece relative motion between the flexible brush and the workpiece is responsible for abrasion. The material will be removed particularly form the peaks of the workpiece surface in the form of chips.

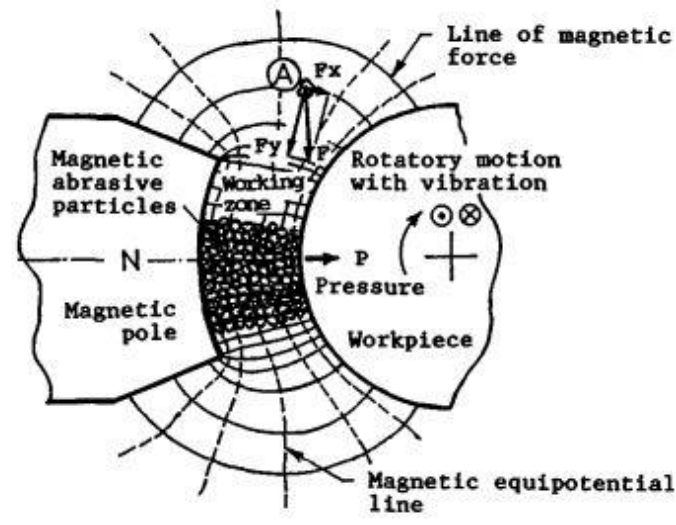

Fig. 1. Magnetic Abrasive Machining of cylindrical surface [2]

Magnetic abrasive finishing process explored numerous opportunities of improving quality of soft and hard workpieces with reduced residual stresses, minimum metallurgical damage and superior surface finish of nanoscale $(0.05 \mu \mathrm{m})$. Bayoumi et al. (1995) reported Fatigue life of the mechanical component is very sensitive to surface finish \& surface treatment [1]. Shinmura et al. (1990) reveals MAF-analysis, influence of magnetic abrasive particle size on material removal rate and surface finish of SS41 steel [2]. Magnetic abrasive machining uses very low forces and loose abrasive particles for superior finish than other surface finishing lapping [4]. Chang et al. (2001) reported sintered magnetic abrasive less economical due to complex product process relative to unbounded magnetic particle (specifically Silicon Carbide) although bonded and unbonded abrasives along with ferromagnetic grits have been used. UMA are as good as sintered magnetic abrasive [3]. Yan et al. has compared surface finish of MAF with other process like as EDM. EDM surface finish $(0.1 \mu \mathrm{m})$ in more and it takes more time, expensive while MAF produces superior refined surface finish $(0.05 \mu \mathrm{m})$ in less time and no recast layer remains on the workpiece [26].

Vibration assisted MAF is more suitable for finishing hard materials such as Magnesium alloy and AISI202 stainless steel tubes [9, 10]. Fox et al. (1995) showed that higher magnetic flux density can assist in achieving better surface finish on non-magnetic stainless steel rods [11]. Kim \& Choi evaluate formulae of estimating pressure and magnetic field density [5]. Rahul et al. carried an effort to measure the normal force and finishing torque during ultrasonic assisted magnetic abrasive finishing (UAMAF) using dynamometer was considered with process parameters as the voltage, rotation of electromagnet, working gap, $\mathrm{SiC}$ abrasive weight, pulse on time of ultrasonic vibration [12]. Riveros et al. aimed to study the flat silicon surface finishing characteristics of MAF by analyzing nanoscale surface feature changes in geometry and texture [13]. It was reported that magnetic field distribution in processing region, studied the effects of fluctuating magnetic field cluster on finishing surface and abrasive behaviour [16]. Graziano et al. studied the dominant parameters for controlling the lay with MAF on flat disks and demonstrates the feasibility of MAF to alter the lay while controlling the surface roughness [14].Some researchers had conducted MAF experiment using alternating current magnetic field and observed relative less effective for experimental setup $[15,16,17]$.

\section{B. Mechanism of Electrochemical Machining}

A Direct Current power supply is applied between the workpiece (anode) and the tool (cathode), which are separated by a small gap ( $1 \mathrm{~mm}$ to $2 \mathrm{~mm}$ ). The electrolyte flows between two electrodes of constituent electrochemical process. Many redox reactions occur at the cathode and anode electrode portion dipped in the electrolyte. The material removal mechanism is combined effect of Faraday's law. Material removal rate $Q_{t h}$ is material removal rate, $v$ is the valence of dissolution, a is molecular weight of the metal, F is Faraday's constant, $\mathrm{t}$ is time of machining and $\mathrm{I}$ is applied DC current Final mathematical expression

$$
Q_{t h}=\frac{I t a}{v F}
$$

The material removal is based on following factors

$\begin{aligned} \text { i. } & \text { Anodic reaction and current efficiency } \\ \text { ii. } & \text { Mass transport controlled anodic dissolution and } \\ \text { iii. } & \text { Current distribution and shape evolution }\end{aligned}$

Chin et al. (1974) reported at lower current density mildsteel surface is covered with an electronically conductive $\mathrm{Fe}_{3} \mathrm{O}_{4}$ film and current is consumed mainly in the generation of oxygen while at higher current densities bare metal surface exposed to the electrolyte begins to dissolve at high rate [18]. Bannard et al. (1976) reported effect of electrolyte velocities on efficiency of dissolution of mild steel at fixed current density $\left(25 \times 10^{4} \mathrm{Am}^{-2}\right)$ using electrolyte $\mathrm{NaCl}, \mathrm{NaNO}_{3}$ and $\mathrm{NaClO}_{3}$ [19]. Haisch et al. (2001) has reported that electrochemical machining of steel $100 \mathrm{Cr} 6$ in aqueous $\mathrm{NaCl}$ and $\mathrm{NaNO}_{3}$ solution. It was observed that the $\mathrm{NaCl}$ electrolyte treated is loosely bounded layer while $\mathrm{NaNO}_{3}$ treated surface is strongly attached to steel [20]. Curtis et al. (2009) have evaluated hybrid Electrochemical/Electrolytic point grinding (ECPG) with small wheels for machining of complex turbine/ compressor blade root mounting slots in aero engine discs. The electroplated wheel gave better performance [22]. 


\section{Mechanism of Electrolytic Magnetic Abrasive Machining}

In EMAM process, both well established ECM process and MAM process equipments are systematically arranged and synergistically controlled. As DC power supply is applied on tool electrode (cathode) and workpiece (anode) terminals separated by small gap (up to $3 \mathrm{~mm}$ ) and filled with electrolyte of electrochemical machining process, metal dissolution initiates. A passive layer is formed on workpiece (anode) surface reacted during electrochemical machining.

The passive layer will be removed gently by flexible magnetic abrasive brush formed in MAM during processing, which further exposes the new metal surface. The electrochemical reaction takes place in the electrode gap where magnetic field is already present. The magnetic field lines are moving from $\mathrm{N}$-pole and to S-pole of magnet, whereas electrified in the electrode gap are moving from cathode (tool electrode) to anode (workpiece). The magnetic field is perpendicular to electric field. The negative ions are jointly activated by the Lorentz force and the electrical field force. The Lorentz force (N) acting on the electrolytic ions due to combined effect of electric and magnetic field is given below.

$$
\vec{F}=q(\vec{E}+\vec{v} \times \vec{B})
$$

Where, $q$ and $v$ represents charge $(C)$ and velocity vector $(\mathrm{m} / \mathrm{s})$ of the electrolytic ion respectively. $\mathrm{E}$ and $\mathrm{B}$ vectors representing vector of electric field intensity $(\mathrm{V} / \mathrm{m})$ and magnetic field density (T) respectively. By using Newton's second law of motion, it is observed that electrolytic ions move in a complex cycloidal path. Hence, peak points and upper irregularities of workpiece surface react rapidly and form passive layer and that layer is gently removed by abrasion action of magnetic abrasive particles.

The basic parts used for EMAM experimental setup development were Electromagnet, Power Supply, Electrolyte or Slurry supply system and Vibration system depending upon their research objective.

Fang et al. (2002) employed magnetic electrochemical finishing machining experimentally and tracked equation of ionic motion of electrolyte under effect of magnetic field [24]. Fig. 2 schematically depicts the EMAM setup for better machining and finishing [25]. The parts numbering shows 1DC power source, 2- brush, 3- electrode, 4- magnetic abrasives, 5- workpiece, 6- magnetic poles, 7- electrolyte reservoir, 8- electrolytic tank, 9- electrolyte 10- filter, 11pump, 12- Metering Valve, 13- flow gauge.

As shown in fig. 2, a pair of magnetic poles of electromagnet, electrolyte supply system, axial vibration system and DC Power source were assembled to perform experimentation.

When magnetic field influence the electrolytic process, the path of negatively charge ions toward the anode surface changes to cycloid curve under the effect of Lorentz force. It causes rapid electrochemical reaction at peaks or irregularities. Then passive layer is produced which is easily removed by magnetic abrasive particles. Repeating the same process for experiment duration leads to smooth finish of workpiece surface.

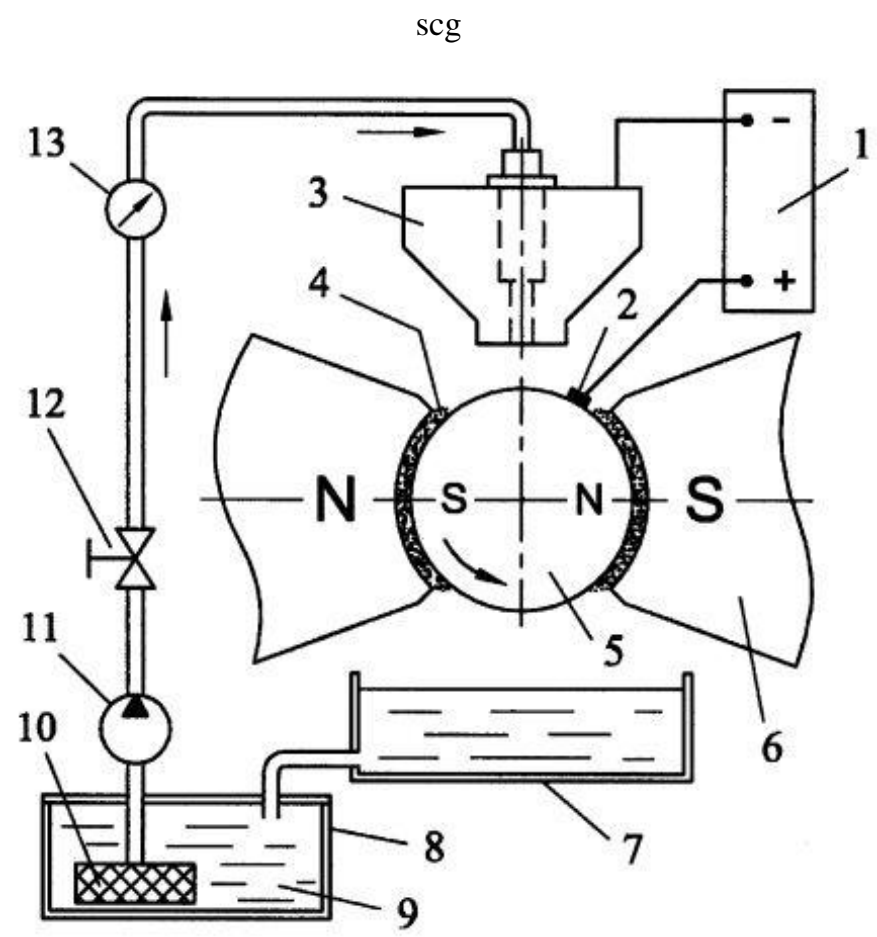

Fig. 2. Schematic diagram of Electrolytic Magnetic Abrasive Machining of cylindrical workpiece [23]

Yan et al. (2003) author has experimentally compared EMAM with MAM using process parameters i.e. rate of workpiece revolution, electrode gap, and electrolytic current while observing performance parameters such as material removal and surface roughness. The Digital Microbalance and Surface Roughness Tester were used for measuring material removal and surface roughness respectively.

El-Taweel reported modelling of experimental process on $6061 \mathrm{Al} / \mathrm{Al}_{2} \mathrm{O}_{3}(10 \% \mathrm{wt})$ composite and found increase in machining efficiency by $147.6 \%$ while surface finish improved by $33 \%[26]$.

Judal et al. (2013) performed EMAM process experimentally on cylindrical workpiece of AISI304 steel and observed EMAM process was better than MAF and ECM process. They also showed that their cumulative effect evolved a better hybrid process for machining and finishing of cylindrical workpiece external surface [27, 28].

There is extra material removal in EMAM process and with increase in electrolytic current the extra material removal further increases. It was found that extra material removal increase up to $84 \%$ by conducting experiment on EMAM setup at $2 \mathrm{~A}$ electrolytic current. They observed variation of surface roughness with electrolytic current. It was found that at $.5 \mathrm{~A}$ electrolytic current the surface finish was $0.27 \mu \mathrm{m}$ after MAM, same material surface finish was $0.2 \mu \mathrm{m}$ after ECM 


\section{Asia Pacific Journals}

while after EMAM surface finish became $0.18 \mu \mathrm{m}$. Herein as the electrolytic current was increased from $0.5 \mathrm{~A}, 1.0 \mathrm{~A}, 1.5 \mathrm{~A}$ and 2.0A the surface finish further increased. It was found that surface roughness dropped to $0.08 \mu \mathrm{m}$ for $2 \mathrm{~A}$ electrolytic current.

Liu et al. (2014) performed experimentation of EMAM on Al6061 on flat workpiece and observed effect of working gap on surface roughness [29]. Ridha et al. (2015) employed internal EMAM process on aluminum A16063. They performed finishing in fixed ratio 2:9 for ECM and MAF respectively for mirror finish. Surface photographs were observed using Scanning Electron Microscope after finishing, where $0.030 \mu \mathrm{m}$ surface finish was achieved [30]. Du et al. (2015) employed EMAM experiment on Nickel-based superalloy GH4169plane workpiece. Original surface morphology was $33.1 \mu \mathrm{m}$ while after conducting MAF the surface height reduced to $16 \mu \mathrm{m}$ while after performing EMAM process surface topography height reduced to $8.5 \mu \mathrm{m}$. Hence, workpiece surface became more dense and uniform after EMAM experimentation [31].

\section{CONCLUSIONS}

The conclusions drawn from the reviewed literature are summarized below,

1. The material removal improved up to $84 \%$ during hybrid EMAM machining process relative to MAM and ECM process.

2. EMAM process reduces surface roughness of the workpiece for stipulated time by $33 \%$.

3. The surface texture improved using EMAF process relative to constituent processes.

4. Only specific superalloys (GH4169) and composite materials $\left(6061 \mathrm{Al} / \mathrm{Al}_{2} \mathrm{O}_{3}\right)$ has been experimented.

5. As the higher DC current is supplied to electromagnet, proportionately higher magnetic flux density is induced between magnetic poles in small gap and consequently machining pressure acting on magnetic abrasive particles is enhanced. It leads to more material removal.

6. Circumferential marks, lays or patterns on machining surface are significantly removed under vibration assisted in perpendicular to direction of machining in the form of microchips in MAF and similarly in EMAM. The vibration helps in proper mixing of magnetic abrasive particles.

7. Vibration assists self sharpening of magnetic abrasive particles which otherwise becomes ineffective during machining and finishing.

\section{Acknowledgment}

The authors are grateful to Council of Scientific and Industrial Research, New Delhi, India for its financial support. The work presented in this article is a part of CSIR project no. 22/(0644)/13/EMR-II.

\section{References}

[1] Bayoumi M.R. and Abdekllatif A.K., "Effect of surface Finish on Fatigue Strength", Engineering Fracture Mechanics, (1995), 51(5), pp. 861-870.

[2] T. Shinmura, K. Takazawa, E. Hatano and M. Matsunaga, "Study on Magnetic Surface Finish", Appals of CIRP, 39(1), (1990), pp. 325-328.

[3] G.W. Chang, B. H. Yan and R.T. Hsu, "Study On Cylindrical Magnetic Abrasive Finishing Using Unbonded Magnetic Abrasives", Int. J. of Machine Tool and Manufacture, 42, (2001) ,pp. 575-583.

[4] T. Shinmura and H. Yamaguchi, "Study on A New Internal Finishing Process By The Application of Magnetic Abrasive Machining", International Journal JSME, Series C, 38(4), (1995), pp. 798-804.

[5] Kim J. D. and Choi M. S., "Simulation for the prediction of surfaceaccuracy in magnetic abrasive machining", Journal of Materials Processing Technology 53, (1995), pp. 630-642.

[6] H. Yamaguchi and T. Shinmura, "Study on an Internal Magnetic Abrasive Finishing Using a Pole Rotation System", International Journal of Int. Societies for Precision Engg. And Nano Technology, 24, (2000), pp. 237-244.

[7] Wu J., Zou Y. and Sugiyama H. "Study on ultra-precision magnetic abrasive finishing process using low frequency alternating magnetic field", Journal of Magnetism and Magnetic Materials, (2015), 386, pp. 50-59

[8] J. L. Lyon, K. J. Stevenson, "Anomalous Electrochemical Dissolution and Passivation of Iron Growth Catalysts in Carbon Nanotubes". American Chemical Society, 23(22), (2007), pp. 11311-11318.

[9] S. Yin and T Shinmura, "Vertical vibration assisted magnetic abrasive finishing and deburring for magnesium alloy". Internaional Journal of Machine Tools \& Manufcturing 44, (2004) ,pp. 1209-1303,

[10] A. Singh and V. Yadava, "Axial-Vibration assisted CylindricalMagnetic Avrasive Finishing of AISI202SS tubes", An International conference on Precision, Meso, Micro and Nano Engineering, vol 78/1-5 (2015)

[11] M. Fox, K. Agarwal and R. Komanduri, "Magnetic Abrasive Finishing of Rollers" pp. 90-93, 1994

[12] R.S. Mulik, and P.M. Pandey, "Experimental Investigations and Modelling of Finishing Force and Torque in Ultrasonic Assisted Magnetic Abrasive Finishing", ASME Journal Manufacturing Science Engineering, 134 (5), (2012), pp. 1-11.

[13] Riveros R.E., Hann J.N., Taylor C.R., and Yamagauchi H., "Nanoscale Surface Modifications by Magnetic Field-Assisted Finishing", ASME Journal Manufacturing Science Engineering, (2013), 135/051014-1.

[14] A. A.Graziano, V. Ganguly, T. Schmitz and H. Yamaguchi, "Control of Lay on Cobalt Chromium alloy Finished Surfaces Using Magnetic Abrasive Finishing and Its Effect on Wettability", ASME Journal Manufacturing Science Engineering, (2014), 136/031016-1.

[15] T. Shinmura, E. Hatano and K. Takazawa, "The Development of Magnetic Abrasive Finishing And Its Equipment By Applying A Rotating Magnetic Field", Bulletin Japan Society of Mechanical Engineering, 29(258),(1986), pp 4437-4443

[16] T. Shinmura, H. Yamaguchi and Y. Shinbo, "A New Internal Finishing Process of A Non-Ferromagnetic Tubing By Applying A Rotating Magnetic Field”, Precision Engineering, 26(4), (1992), pp 302-304

[17] H. Yamaguchi, T. Shinmura and M. Takenaga, "Development of A New Precision Internal Machining Process Using An Alternating Magnetic Field”, Precision Engineering, 27, (2003), pp 51-58

[18] D-T Chin, and K-W Mao, "Transpassive dissolution of mildsteel in $\mathrm{NaNO}_{3}$ electrolytes", Journal of Applied Electrochemistry, 4, (1974), pp. $155-161$.

[19] J. Bannard, "Effect of flow on the dissolution efficiency of mild steel during ECM", Journal of Applied Electrochemistry, 7, 1977, pp. 267270

[20] T. Haisch, E. Mittemeijer and J.W. Schultze, "Electrochemical machining of the steel $100 \mathrm{Cr} 6$ in aqueous $\mathrm{NaCl}$ and $\mathrm{NaNO}_{3}$ solutions: microstructure of surface films formed by carbides", Electrochimica Acta, 2011, 47,235-241. 


\section{Asia Pacific Journals}

[21] V. B. Singh and A. Gupta, "Active, passive and Transpassive dissolution of In-718 in anodic solutions", Materials Chemistry and Physics 85, (2004), pp. 12-19.

[22] D.T. Curtis, S.L. Soo, D. K. Aspinwall and C. Sage, "Electrochemical superabrasive machining of a nickel-based aeroengine alloy using mounted grinding points", CIRP Annals-Manufacturing Technology 58, (2009), pp. 173-176

[23] X. Fang, N. Qu, Y. Zhang, Z. Xu, and Z. Di, "Effects of pulsating electrolyte flow in electrochemical machining", Journal of Materials Processing Technology, 214, 2014, pp. 36-43.

[24] J.C. Fang, Z. J. Jin,W.J. Xu and Y.Y. Shi, "Magnetic electrochemical finishing machining", Journal of Material Processing Technology 129 (2002), pp. 283-287

[25] B. H. Yan, G. W. Chang ,T.J. Cheng, and R. T. Hsu, "Electrolytic Magnetic Abrasive Finishing", International Journal of Machine Tools \& Manufacturing, 43, (2003), pp. 1355-1366.

[26] T. A. El-Taweel, "Modelling and analysis of hybrid electrochemical turning-magnetic abrasive finishing of $6061 \mathrm{Al} / \mathrm{Al}_{2} \mathrm{O}_{3}$ composite" International Journal Advance Manufacturing Technology, 37, (2005), pp. 705-714.

[27] K. B. Judal and V. Yadava, "Electrochemical Magnetic Abrasive Machining of AISI304 Stainless Steel Tubes", International Journal Precision Engineering Manufacturing, 14 (01), (2013), pp. 37-43.
[28] K. B. Judal and V. Yadava, "Cylindrical Electrochemical Magnetic Abrasive Machining of AISI-304 stainless steel", Material \& Manufacturing Processes, 28 (04), (2013), pp. 449-456.

[29] G. Y. Liu, Z. N. Guo, S.Z. Jiang, N. S. Qu and Y.B. Li, “ A study of processing Al6061 with electrochemical magnetic abrasive finishing" International Conference on High Performance Cutting, (2014), 14,pp. 234-238.

[30] M. M. Ridha, Z. Yanhua, S. Hitoshi, "Development of a New Internal Finishing of Tube by Magnetic Abrasive Finishing Process Combined with Electrochemical Machining”,International Journal of Mechanical Engineering and Appliactions, 3(2), (2015), pp. 22-29.

[31] Z. W. Du, Y. Chen, K. Zhou, C. Li, "Research on the electrolyticmagnetic abrasive finishing of nickel- based superalloy GH4169", International Journal Advance Manufacturing Technology 81, (2015), pp. 897-903, DOI 10.1007

[32] J. D. Kim, Dong-Xie Jin and Min-Seog Choi, Study of the effect of a Magnetic Field on an electrolytic Finishing Process, International Journal of Mach. Tools Manufacturing, 37, 4 pp. 401-408, 1997

[33] J. D. Kim, Dong-Xie Jin and Min-Seog Choi , Development of the magneto-electrolytic abrasive polishing system (MEAPS) and Finishing Characteristics of a Cr-coated Roller, International Journal of Mach. Tools Manufacturing, 37, 4 pp. 401-408, 1997 